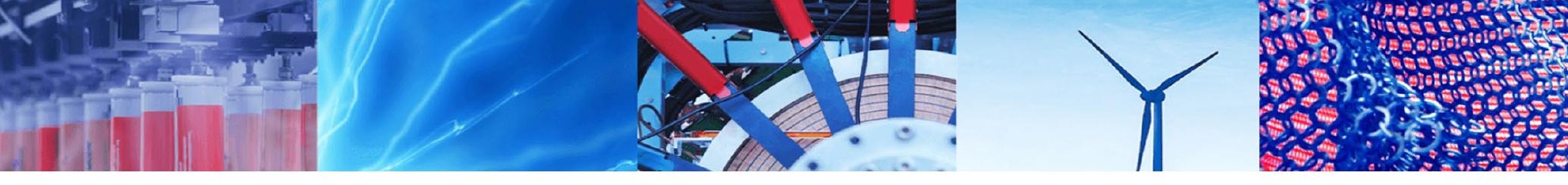

Research Article

\title{
Effect of nano-zerovalent iron incorporated polyvinyl-alginate hybrid hydrogel matrix on inhibition of corrosive bacteria in a cooling tower water environment
}

\author{
Adikesavan Selvi ${ }^{1}$ (1) $\cdot$ Azhagesan Ananthaselvam $^{2} \cdot$ Jayaraman Narenkumar $^{3} \cdot$ Arumugam Arul Prakash $^{1}$. \\ Jagannathan Madhavan ${ }^{4} \cdot$ Aruliah Rajasekar $^{1}$ (i)
}

(c) Springer Nature Switzerland AG 2019

\begin{abstract}
Microbial-induced corrosion (MIC) is an insidious process caused by microbial growth on metals. Among many metals, aluminium, brass, mild steel, stainless steel and carbon steels are more vulnerable to MIC. The present study investigates one of the effective corrosion protection strategies using hybrid hydrogel coating. In this regard, the anti-corrosive activity of $n$-zerovalent iron (nano-ZVI) incorporated polyvinyl-alginate (PVA) hybrid hydrogel-coated matrix against MIC on aluminium, Al 1100 metal, was tested. The study was conducted against corrosion-inducing bacteria, Terribacillus aidingensis EN3 (Accession number: KR183874), isolated from cooling tower water system. The antibacterial results of nano-ZVI showed a diameter of zone of inhibition at $10 \mathrm{mg} / \mathrm{mL}$. Hybrid hydrogel matrix was employed against the MIC in cooling tower water-containing systems, I, II and III, IV along with a control. The results of the study were supported with weight loss (WL) analysis and electrochemical impedance spectroscopy (EIS) studies. WL results showed a reduced rate of $0.08 \mathrm{~mm} / \mathrm{y}$ corrosion in hybrid hydrogel system than the other systems. The EIS studies showed higher charge transfer resistance $\left(R_{\mathrm{ct}}\right)$ of $14.53 \Omega$ and solution resistance of $3.8 \Omega$. These results confirmed the presence of nano-ZVI in hybrid hydrogel acted as an antibacterial agent in the PVA-alginate protective film against corrosion in Al 1100. Thus, the obtained results evidenced the novel idea of hydrogel matrix to act as an anti-corrosive film in the cooling tower system.
\end{abstract}

Keywords Microbial-influenced corrosion · PVA-alginate · Zerovalent iron nanoparticles · Hybrid hydrogel

\section{Introduction}

Corrosion process is a destructive phenomenon that greatly affects the appearance of the metals, besides its economic effects in terms of equipment and other structural component failures [27]. Of various corrosions, microbial-influenced corrosion (MIC) involves the participation of microorganisms through the secretion and accumulation of microbial metabolites such as, extracellular polymeric substances (EPS), acids, sulphides and ammonia [31, 39]. These compounds are found to initiate physical and chemical interaction between the metal and the microbes through electrochemical processes [35]. In many pipeline industries like, oil, gas and cooling tower systems (CTS),

Electronic supplementary material The online version of this article (https://doi.org/10.1007/s42452-019-0443-2) contains supplementary material, which is available to authorized users.

Adikesavan Selvi, seljeev@gmail.com; selvi.a2013@vitalum.ac.in; $\bowtie$ Aruliah Rajasekar, rajasekargood@gmail.com; rajasekargood@tvu.edu.in | ${ }^{1}$ Environmental Molecular Microbiology Research Laboratory, Department of Biotechnology, Thiruvalluvar University, Serkadu, Vellore, Tamil Nadu 632115, India. ${ }^{2}$ Centre for Nanoscience and Nanotechnology, Sathyabama Institute of Science and Technology (Deemed to be University), Chennai, Tamil Nadu 600119, India. ${ }^{3}$ Corrosion and Protection Division, Shenyang National Laboratory for Materials Science, Northeastern University, Shenyang 110819, China. ${ }^{4}$ Solar Energy Lab, Department of Chemistry, Thiruvalluvar University, Serkadu, Vellore, Tamil Nadu 632115, India.

SN Applied Sciences (2019) 1:424 | https://doi.org/10.1007/s42452-019-0443-2

Received: 11 January 2019 / Accepted: 2 April 2019 / Published online: 6 April 2019 
etc., with high-tech equipment facilities, MIC still continues to be a major threat, contributing to the blockage of pipelines, failure of operations and high maintenance costs [7, 42]. In addition, MIC was also reported to be responsible for the reduction in cooling efficiency and loss of thermal exchange in CTS [47].

Aluminium (AI) and its alloys are commonly used in power plants employing dry cooling tower systems owing to its low cost and high stability characteristics $[4,14]$. However, their application in re-circulating water systems like CTS needs more research focus to address their corrosion problems. In general, an oxide layer on the aluminium surface acts a protective barrier against corrosion for a short span of time. But, any mechanical damage to this layer in the form of extreme $\mathrm{pH}$ fluctuations and high temperatures in CTS will lead to violent corrosion of aluminium by pitting process, in which the self-repair will not be possible [17]. Extreme acidic $\mathrm{pH}$ produces $\mathrm{Al}^{3+}$ ions, whereas extreme alkaline $\mathrm{pH}$ yields $\mathrm{Al}(\mathrm{OH})_{4}$ ions as corrosion products. Pitting usually occurs in metals like aluminium, magnesium, stainless steel, titanium and copper that is covered with a transparent, very thin, passive oxide film produced by fabrication or environmental reaction $[10,22]$. A report on failure of a Russian power plant due to the deposition of more than $10 \%$ of aluminium silicate in CTS is one of the classic examples of aluminium corrosion [24]. Aluminium corrosion can cause significant damage to boilers and turbine flow pipelines. We have used commercially available Al 1100, an aluminium-based alloy, composed of $99 \%$ aluminium. It is also considered to be one of the mechanically strongest alloys among the commercially available aluminium-based alloys series [21,28].

Several other reports on the effect of various factors, like thermo-physical and chemicals, influencing the corrosion rate of aluminium and its alloys are available in the literature $[1,9,44]$. Therefore, it is imperative to find some effective formulations to address aluminium corrosion. Among various corrosion inhibitors, chemical inhibitor materials were reported to be economical, easy addition, offers good protection and most effective in controlling the metal dissolution in tanks, pipelines, shipping vessels, etc. [7, 42].

Application of protective coatings is regarded as one of the successful approaches to combat corrosion process in different metallic systems. These protective coatings can be of inorganic, organic polymers or hybrid polymeric layers. As reported by many, these protective coatings act as a physical barrier in between the metal surface and the environment, thus limiting the penetration of the corrosive microbes [50]. The coatings can be thick or thin depending on the material used for coating. However, thick and hybrid sol-gel coatings can confer good protection with barrier properties than thin film coatings. Various nanoparticles such as zirconia, silica, ceria and a few others were successfully used as hybrid materials in sol-gel protective coatings on different metal substrates, including aluminium and its alloys $[11,12,29,53]$.

In this regard, we have chosen polyvinyl alginate (PVA) as a hydrogel matrix in our study. Besides being non-toxic and non-carcinogenic, PVA possesses high water affinity, good tensile stress, wear resistance, good biocompatibility, minimal cell and protein adhesion and excellent electrical insulation $[15,41]$. In addition, the use of nanoscale has stimulated the development of cost-effective technologies for environmental treatment options [25, 52]. Nanoscale zerovalent iron (nano-ZVI) is reported as one of the potential nanomaterials to be used in environment remedial applications $[18,40]$. These nanomaterial properties have been made use by immobilizing nano-ZVI in PVA-alginate hydrogel to demonstrate corrosion studies against biocorrosion of aluminium (Al 1100) metal coupon. To the best of our knowledge, this is the first anti-corrosive report on hybrid hydrogel towards aluminium metal.

\section{Materials and methods}

\subsection{Chemicals and reagents}

Polyvinyl alcohol, sodium alginate and calcium chloride were purchased from Himedia Laboratories Pvt, Ltd., India. All reagents were of analytical grade and used without further purification.

\subsection{Microorganism}

The microorganism used in the present study is the corrosion-inducing bacterium isolated by Narenkumar et al. [32] from cooling tower water (CTW) system. The organism was named as Terribacillus aidingensis EN3 and was submitted to The GenBank, NCBI database under the accession number (KR183874).

\subsection{Synthesis of nano-ZVI}

The chemical synthesis of nano-ZVI was done following the method of Sun et al. [45]. Equal volumes of sodium borohydride $(0.94 \mathrm{M})$ and ferric chloride $(0.18 \mathrm{M})$ were weighed separately and thoroughly mixed and slowly added drop wise into sodium borohydride (IM) solution with vigorous stirring ( $400 \mathrm{rpm})$. The formation of nanoparticulate iron was noted by an immediate change in the colour (black) of the solution. Then, the iron nanoparticles were separated by vacuum filtration $(0.2 \mu \mathrm{m})$. The synthesized zerovalent iron particles were finally washed 
several times using deionized (DI) water followed by ethanol before use. It can also be stored in water containing $5 \%$ ethanol.

\subsection{Antibacterial effect of nano-ZVI on growth of Terribacillus aidingensis EN3}

The antibacterial effect was studied using agar-well diffusion method with various concentrations of nano-ZVI ranging from 10 to $25 \mathrm{mg} / \mathrm{mL}$ [40]. Mueller-Hinton agar plates were prepared with a lawn culture of $T$. aidingensis EN3. The wells were cut under sterile conditions with the help of gel cutter. To this, $50 \mu$ of nano-ZVI at a varying concentrations ranging from 5 to $25 \mathrm{mg} / \mathrm{mL}$ was loaded onto each well. The test plates were incubated for $24 \mathrm{~h}$ at $37^{\circ} \mathrm{C}$. After incubation, the zone of inhibition around each well was noted. The least concentration that showed inhibition was fixed as the diameter of the zone of inhibition (DZI). The experiments were repeated thrice for statistical data analysis.

\subsection{Biofilm assay}

The biofilm assay procedure was followed according to O'Tool et al. [34]. Overnight grown culture of the EN3 strain grown in nutrient broth was diluted with fresh nutrient broth in 1:20 ratio. In a sterile 96-well polystyrene microtitre plate, an optimized DZI concentration of $10 \mathrm{mg} / \mathrm{mL}$ of the nano-ZVI was added to the microtitre wells. This was followed by the addition of $100-\mu \mathrm{L}$ cultures into microtitre wells with gentle mixing. $100 \mu \mathrm{L}$ of plain diluted culture in the wells served as a control. The plate was incubated at $37^{\circ} \mathrm{C}$ temperature for $24 \mathrm{~h}$. After incubation, the culture was removed and washed with phosphate-buffered saline (PBS). $120 \mu \mathrm{L}$ of freshly prepared crystal violet dye solution was added and incubated again at room temperature for $20 \mathrm{~min}$. At the end of the duration, $125 \mu \mathrm{L}$ of acetic acid was added to the same and incubated again at $37^{\circ} \mathrm{C}$ for $15 \mathrm{~min}$. Then, the obtained result was read at $570 \mathrm{~nm}$ using microplate reader (Model: 680, Bio-Rad, UK).

\subsection{Preparation of nano-ZVI-PVA (hybrid hydrogel) matrix}

Firstly, $20 \mathrm{~g} / \mathrm{L}$ of PVA and $10 \mathrm{~g} / \mathrm{L}$ of sodium alginate was weighed and mixed in 2:1 ratio [41]. Both were added to double distilled water and heated at $80{ }^{\circ} \mathrm{C}$ for about 45 min, until a uniformly dissolved suspension was obtained. The suspension was allowed to cool to room temperature. To this, nano-ZVI was added at a fixed DZI concentration of $10 \mathrm{mg} / \mathrm{mL}$ and mixed well. $0.2 \mathrm{M}$ calcium chloride solution was prepared separately.

\subsection{Al 1100 coupon coating procedure}

The coating of hydrogel matrix was done by immersing the clean, polished aluminium, Al 1100 metal coupon into freshly prepared PVA-alginate hydrogel suspension and immediate dipping in calcium chloride solution (Fig. 1). The dip was left for 10-12 min to stabilize and later stored in the same solution until use.

\subsection{Biocorrosion studies}

The biocorrosion studies were performed according to previously established procedure of Narenkumar et al. [31] with minor modifications. The anti-biocorrosive studies were conducted in three different biotic test systems (Table 1), namely, system I, II, III along with an additional abiotic control system. Polished Al 1100 coupons of dimension $2.5 \mathrm{~cm} \times 2.5 \mathrm{~cm}$ and $1 \mathrm{~mm}$ were used for the study. The coupons were surface sterilized with $70 \%$ ethanol and were dried and stored in a desiccator for further experimental use. All the biotic test system comprised
Fig. 1 a Side and $\mathbf{b}$ flat view of the coated nano-ZVI and PVAalginate coated and uncoated Al 1100 metal coupons

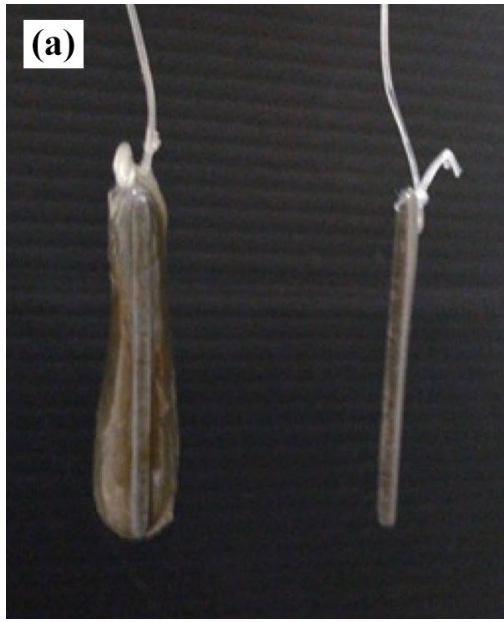

(b)

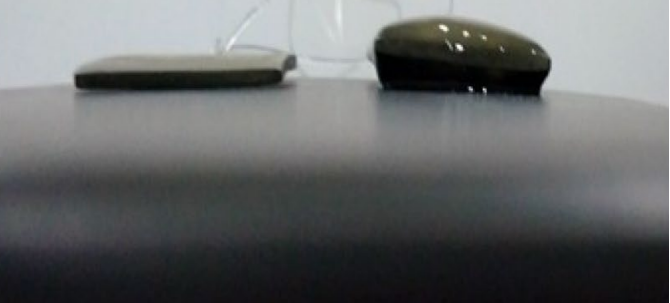

SN Applied Sciences A SPRINGER NATURE journal 
Table 1 Contents of various biocorrosion systems

\begin{tabular}{lll}
\hline S. No. & Biocorrosion systems & Contents \\
\hline 1 & Control & Abiotic system (water sample + Al coupon) \\
2 & System I & Biotic system (water sample + EN3 + Al coupon) \\
3 & System II & Biotic system (water sample + EN3 + n-ZVI + Al coupon) \\
4 & System III & Biotic system (water sample + EN3 + hybrid hydrogel-coated coupon) \\
5 & System IV & Biotic system (water sample +EN3 + PVA-alginate hydrogel) \\
\hline
\end{tabular}

of $200 \mathrm{ml}$ of autoclaved CWS water sample with $1 \%$ of sterile nutrient broth. This was inoculated with $1.0 \mathrm{ml}$ of 24-h freshly grown overnight culture of the strain EN3 $(1.2 \times 10 \mathrm{CFU} / \mathrm{mL})$ and $\mathrm{Al} 1100$ coupon in common. The experiments were carried on with the reaction volume of CWS taken in clean and sterile 500-mL Erlenmeyer flask. The Al 1100 coupons were allowed to get immersed in the system (Fig. 2a-e). This system set-up was incubated for $360 \mathrm{~h}$ or 15 days at $37^{\circ} \mathrm{C}$. Each system was maintained with triplicate coupons to analyse the average rate of corrosion.

\subsection{Characterization studies}

\subsubsection{Biocorrosion weight loss (WL) analysis}

The incubated coupons were carefully separated out at the end of 15 days from their respective systems. The corrosion product (rust) formed on the surface of Al 1100 coupons was collected by scraping off with a clean spatula. The obtained rust particles were crushed into fine powder and stored separately for Fourier-transform infrared spectroscopy (FTIR) (Bruker, Model VERTEX 70) studies [37]. The WL was evaluated by noting the difference in the initial weight of the Al 1100 coupon before and after incubation. Further, the scraped coupons were subjected to pickling at room temperature for $25 \mathrm{~min}$ [36]. The pickling solution comprised of $20 \mathrm{~g}$ of antimony trioxide and $50 \mathrm{~g}$ of stannous chloride in $1 \mathrm{~L}$ of hydrochloric acid.

\subsubsection{Electrochemical studies}

The procedure for electrochemical studies was adopted from Narenkumar et al. [33]. Electrochemical studies (EIS), namely, impedance and Tafel polarization were studied using a three-electrode system ( $\mathrm{CH}$ Instrument Inc., Model $\mathrm{CHI}-608 \mathrm{E}, \mathrm{USA}$ ). $\mathrm{Ag} / \mathrm{AgCl}$ was used as a reference electrode. Al 1100 coupons used for the study was employed as working electrode and platinum (Pt) wire as counter electrode $[30,46]$. The rate of the corrosion was calculated according to the National Association of Corrosion Engineers (NACE) [26] based on the equation given below,

Corrosion rate $=\frac{(K \times W)}{(A \times T \times D)}$

where $K$ is a constant, $T$ is the time of exposure in hours to the nearest $0.01 \mathrm{~h}, A$ is the area in $\mathrm{cm}^{2}$ to the nearest
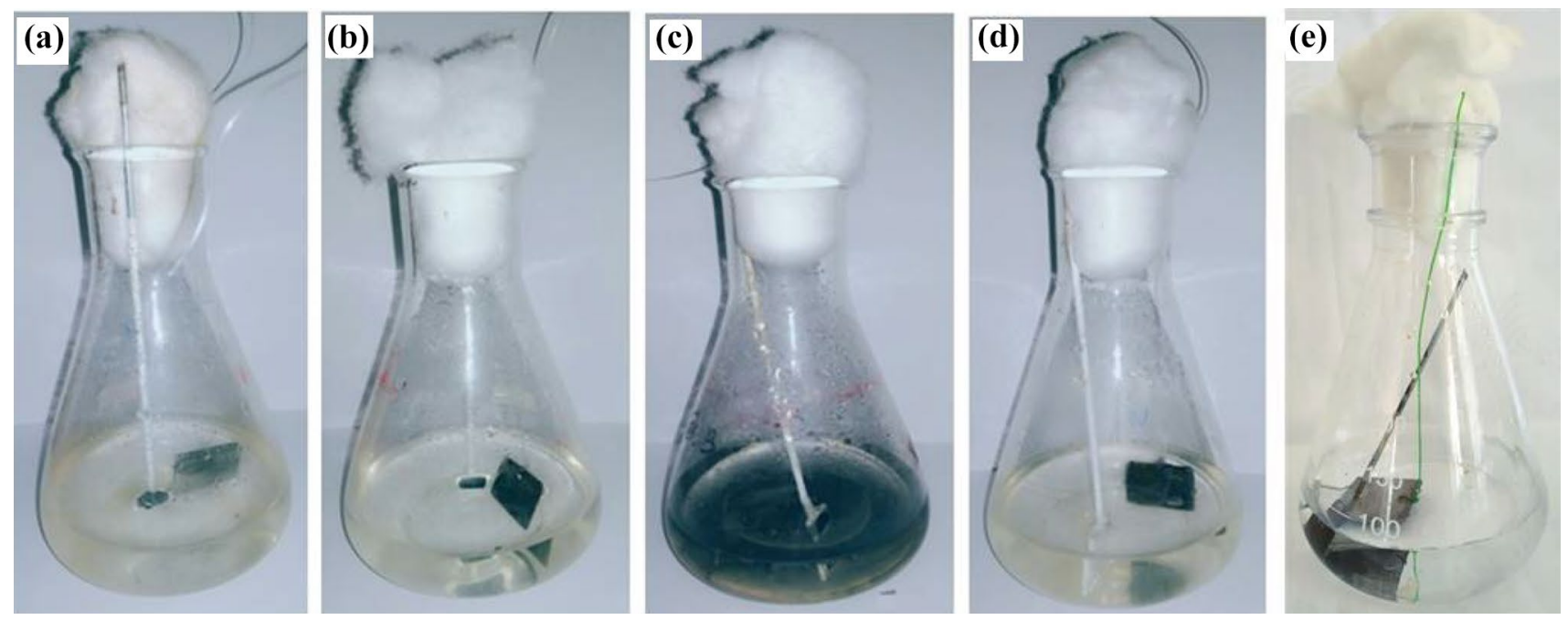

Fig. 2 Preparation of corrosion systems a control system, b system I; system II, c system III and d system IV

\section{SN Applied Sciences}


$0.01 \mathrm{~cm}^{2}, W$ is the mass loss in $\mathrm{g}$, to nearest $1 \mathrm{mg}$ and $D$ is the density in $\mathrm{g} / \mathrm{cm}^{2}$.

\section{Results and discussion}

The antibacterial potential of the nano-ZVI particle on a corrosion-inducing bacterium, T. aidingensis EN3, was calculated by measuring the diameter of the bacterial inhibitory zone in Mueller-Hinton Agar by well diffusion method [6]. It is a measure of the extent of the susceptibility of the strain EN3 towards nano-ZVI. The increasing concentrations of nano-ZVI particle were found to show a proportional dose-dependent trend of the antimicrobial activity with an increase in diameter of zone of inhibition in millimetre $(\mathrm{mm})$. The results showed $0,6,12$, 14 and $17 \mathrm{~mm}$ of diameter of zone of inhibition (DZI) for $5,10,15,20$ and $25 \mathrm{mg} / \mathrm{mL}$ of nano-ZVI concentrations, respectively (Fig. S1). Since, the results showed inhibitory effect from $10 \mathrm{mg} / \mathrm{mL}$ of nano-ZVI, it was fixed as a minimum inhibitory concentration for $T$. aidingensis EN3. Above this concentration, the bacterial cells were found to show poor or no visible growth as a result of inhibitory effect of nano-ZVI. Thus, $10 \mathrm{mg} / \mathrm{mL}$ was fixed as DZI for the corrosion-inducing bacterial strain EN3, and this concentration was used for performing biocorrosion experiments. Suresh et al. [43] too reported on antibacterial activity of silver nanocrystallites on both gram-positive and gram-negative bacteria.
The antibacterial activity of nano-ZVI was further confirmed by performing crystal violet-based biofilm assay with EN3 strain and nano-ZVI. The results showed the plain EN3 strain (control) has the capability to form a biofilm on the microtitre wells, whereas the test wells containing EN3 and nano-ZVI showed significant reduction in biofilm formation. This confirmed the inhibition properties of the nanoparticles.

\subsection{Biocorrosion studies}

As described in Materials and methods section, biocorrosion studies were carried out as three different systems along with a control system. Figure 3a-e shows the system flasks and their respective Al 1100 coupons after 15 day of incubation. The coupons taken out of the control and the systems I, II showed a notable change in the corrosion of Al 1100 (Fig. 3a1-c1). In comparison, system IV with PVAalginate coating showed less corrosion than the system I and II (Fig. 3e1). This can be attributed to the diffusibility characteristics of the PVA-alginate gel that supports microbial growth as reported in earlier studies too [41]. However, the hybrid hydrogel system showed almost no corrosion of the coupon (Fig. 3d1). Generally, PVA is a brittle biomaterial and hence can be combined with other polymers like sodium alginate to confer high stability and mechanical strength [49]. As reported earlier, PVA-alginate hydrogel is a polymeric material with 3D (three-dimensional) networks that possess good elastic properties and
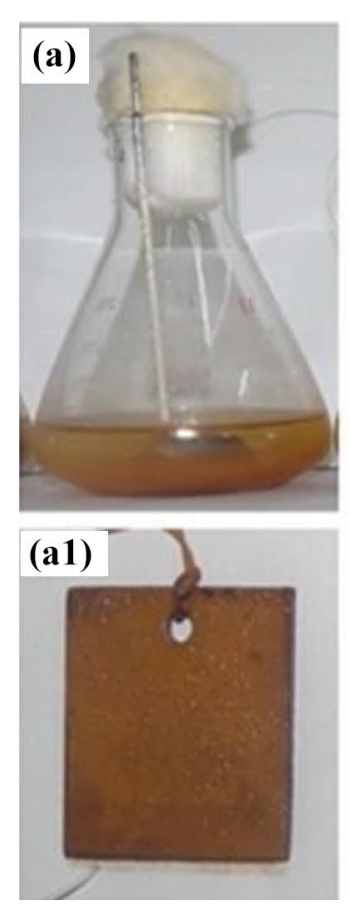
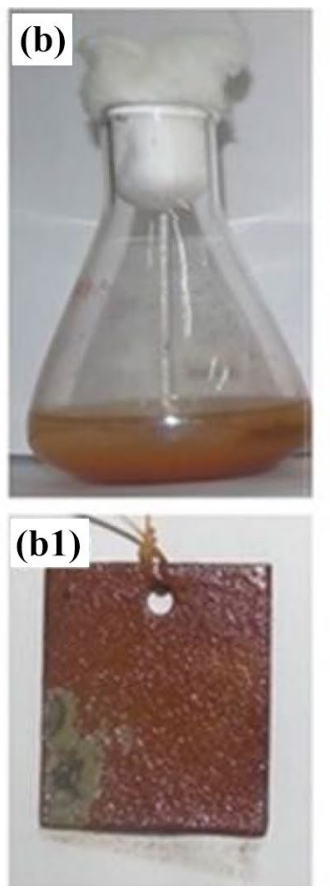
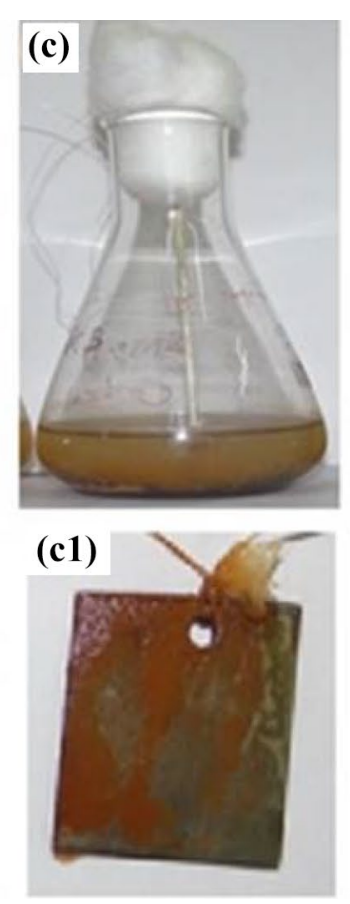
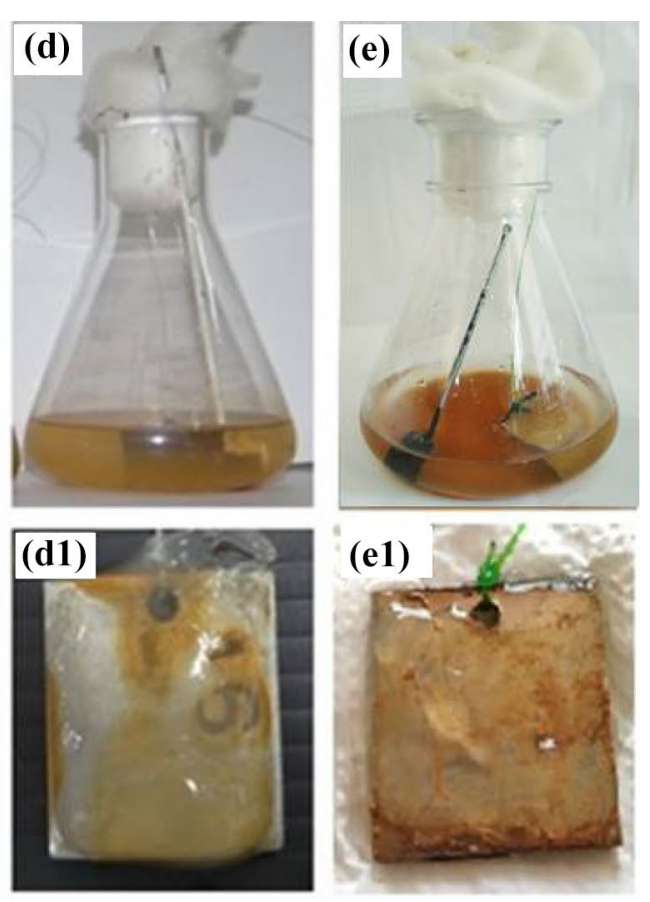

Fig. 3 Biocorrosion control and system flasks (a-d) and their respective Al 1100 coupons (a1-d1) at the end of 15 d of incubation time 
strong mechanical strength $[5,23]$. Moreover, the presence of nano-ZVI in the hydrogel used in the present study confers antibacterial activity against corrosion forming bacteria, T. aidingensis EN3. Preliminary research studies on PVA hydrogel as an anti-corrosive agent has been reported earlier [19]. They reported on PVA hydrogel loaded with modified PESA and imidazoline as an effective corrosion inhibitor. Many reports on significant improvement of metal's corrosion resistance by hybrid sol-gel coatings are available in the literature. In a study by Atik et al. [2], they have developed a hybrid coating of poly methyl methacrylate and $\mathrm{ZrO}_{2}$ and investigated its anti-corrosion behaviour in 316L stainless steel. Similarly, various forms of chemical hydrogel coatings-incorporated inhibitor formulations have also been reported to enhance the corrosion resistance [3]. However, the water-based sol-gel coatings are more cost-effective than the materials used in alcohol-based coating system [8]. An incredible anti-corrosive

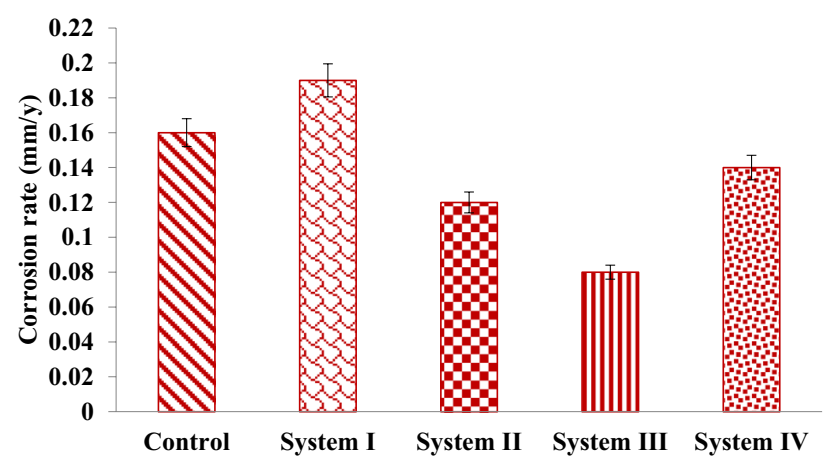

Fig. 4 Graph showing corrosion rate of aluminium (Al 1100) in control and different systems

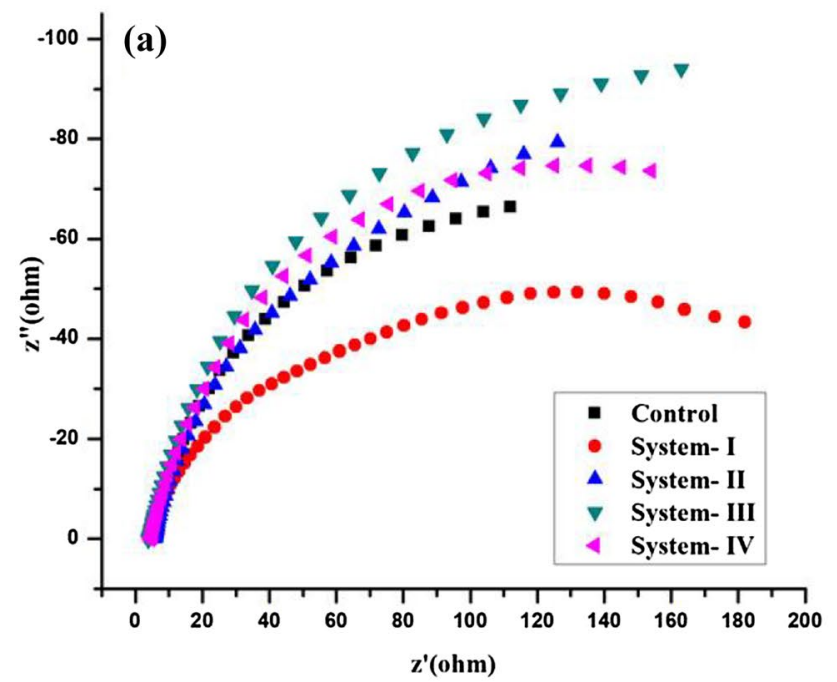

hydrogel device has been reported against carbon steel corrosion by Gu et al. [20]. The obtained results confirmed the coating of the hybrid hydrogel on the coupon served as a potential corrosion inhibitor against Al 1100.

\subsection{Weight loss (WL)}

This biocorrosion results are further validated by calculating the corrosion rate $(\mathrm{mm} / \mathrm{y})$ and the respective results are shown in Fig. 4. As seen from the graph, system III showed the lowest corrosion rate of $0.08 \mathrm{~mm} / \mathrm{y}$ than compared to control $(0.16 \mathrm{~mm} / \mathrm{y})$, system I $(0.19 \mathrm{~mm} / \mathrm{y})$ and system II $(0.12 \mathrm{~mm} / \mathrm{y})$ and system IV $(0.14 \mathrm{~mm} / \mathrm{y})$, respectively. The calculated average WL of $0.054 \mathrm{~g}$ in the system I showed a biocorrosion by strain EN3. However, the calculated WL of control, system II, system III and system IV is found to be $0.047,0.035,0.023$ and $0.041 \mathrm{~g}$, respectively. Dalmoro et al. [13] too reported on silica nanoparticles acting as an anticorrosive agent, thus by forming a protective layer on the metal surface. Another study by Zhou [48] too reported on $\mathrm{SiO}_{2}$ nanoparticles which showed better corrosion performance against mild steel. These results confirmed the active corrosion in all systems except system III, thus confirming the hybrid hydrogel as an effective corrosion inhibitor.

\subsection{Electrochemical impedance studies}

The Nyquist and Tafel polarization curves and related data are presented in Fig. 5a, b and Table 2 for Al 1100 metal in the presence and absence of the bacteria/inhibitor. The charge transfer resistance values of system III seem to be higher $(14.53 \Omega)$ in the hybrid hydrogel coating. This

Fig. 5 Electrochemical impedance studies a Nyquist plot, b Tafel polarization curve

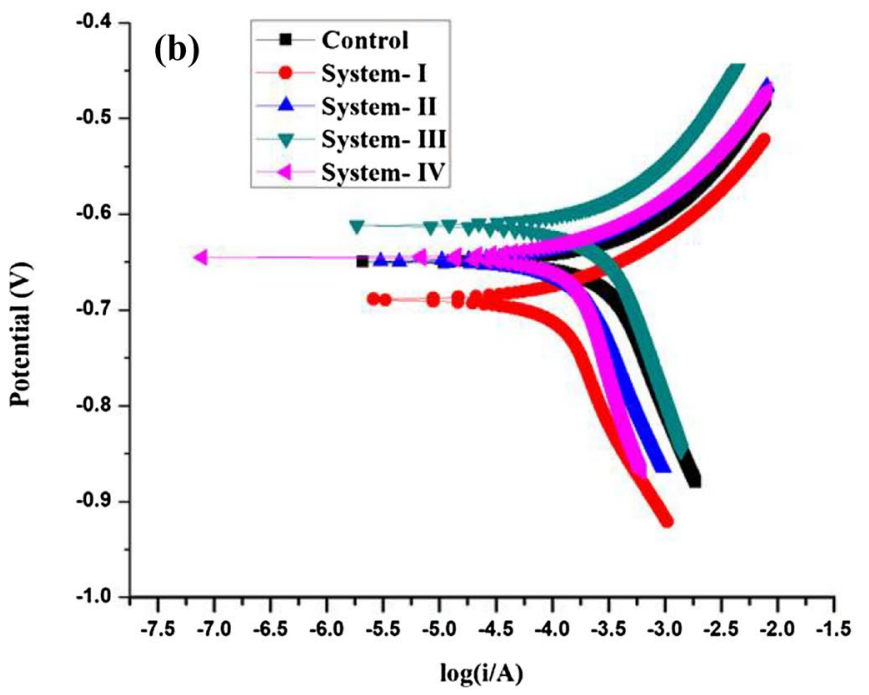


Table 2 Electrochemical impedance spectroscopy and polarization data of the biocorrosion experiments (Systems I, II, III, IV) of Al 1100

\begin{tabular}{|c|c|c|c|c|c|c|c|}
\hline \multirow[t]{2}{*}{ S. No. } & \multirow[t]{2}{*}{ Sample } & \multicolumn{2}{|c|}{ Impedance } & \multicolumn{4}{|c|}{ Polarization } \\
\hline & & $R^{\prime} \mathrm{s}(\Omega)$ & $R_{\mathrm{ct}}(\Omega)$ & $E_{\text {corr }}(\mathrm{mV})$ & $I_{\text {corr }}\left(\mathrm{A} / \mathrm{cm}^{2}\right)$ & ba (mV/decade) & $\begin{array}{l}\text { bc ( } \mathrm{mV} / \\
\text { decade) }\end{array}$ \\
\hline 1 & Control & 1.3 & 10.7 & -668 & $3.9 \times 10^{-5}$ & 9.0 & 3.1 \\
\hline 2 & System I & 5.3 & 1.3 & -682 & $2.1 \times 10^{-4}$ & 10.7 & 2.8 \\
\hline 3 & System II & 4.4 & 10.36 & -666 & $2.9 \times 10^{-5}$ & 9.7 & 3.1 \\
\hline 4 & System III & 3.8 & 14.53 & -651 & $3.7 \times 10^{-6}$ & 9.2 & 2.9 \\
\hline 5 & System IV & 4.1 & 8.45 & -649 & $2.4 \times 10^{-5}$ & 9.7 & 3.0 \\
\hline
\end{tabular}

hydrogel is found to act as a protective layer on the metal surface. On the other hand, the presence of biofilm-forming bacteria, strain EN3 (system II), has resulted in differential aeration/concentration of the bacterial cells, thus changing the local environmental conditions such as, $\mathrm{pH}$, temperature, oxygen depletion, cathodic hydrogen utilization, removal of atoms from metals. This difference in the biocorosion system is evident with a significant reduction in the $R_{\mathrm{ct}}(1.3 \Omega)$ value in the biocorrosion system II [16]. Corrosion of metal iron in an aqueous condition is an electrochemical occurrence, in which the electrons are engendered through the anodic effect of the metal and produces $\mathrm{H}^{+}$ions through dissociation of water, which leads to the hydrogen formation, thus forming a shelter to the metal surface. This reaction is called as cathodic polarization [38]. In case of system II, the presence of nano-ZVI forms an antibacterial film on the metal surface and thus inhibiting the corrosion process. Hence, the presence of nano-ZVI polarization curve was shifted into the cathodic side [33, 51]. The corrosion current $\left(I_{\text {corr }}\right)$ is found to be higher in the biotic system I $\left(2.1 \times 10^{-4} \mathrm{~A} / \mathrm{cm}^{2}\right.$,) than the control system $\left(3.9 \times 10^{-5} \mathrm{~A} / \mathrm{cm}^{2}\right)$. Similarly, the $I_{\text {corr }}$ value for system III is calculated as $2.4 \times 10^{-5} \mathrm{~A} / \mathrm{cm}^{2}$, which is slightly higher than the hybrid hydrogel system. In contrast, hybrid hydrogel system III shows a decrease in $I_{\text {corr }}$ value of $3.7 \times 10^{-6} \mathrm{~A} /$ $\mathrm{cm}^{2}$ for Al 1100 than the control system. These results are found to be in good correlation with the WL data too. Thus, it may be concluded that hybrid hydrogel with nanoZVI forms a protective passive film surface, which greatly inhibited the bacterial attachment of strain, EN3 on the Al metal surface.

\section{Conclusions}

The present study investigated the anti-corrosive activity of the hybrid hydrogel on Al 1100 metal coupon against the biofilm-forming bacterium, T. aidingensis EN3, isolated from cooling tower water. The antibacterial activity of the nano-ZVI was studied by agar-well diffusion method. The characterization studies such as, weight loss, electrochemical and polarization studies of the biocorrosion systems also confirmed the protective anti-corrosive action of the hydrogel. In comparison with other biocorrosion systems, the presence of hybrid hydrogel system exhibited a significant corrosion resistance of $\mathrm{Al} 1100$ that can attributed to the antibacterial activity of the nano-ZVI and hydrogel properties of the PVA-alginate polymer.

Acknowledgements The authors acknowledges Science and Engineering Research Board (SERB), Department of Science and Technology (DST), Government of India for funding this work under N-PDF scheme (File No. PDF/2016/002558) and The Department of Biotechnology (DBT), Government of India for awarding Ramalingaswami re-entry Fellowship (BT/RLF/Re-entry/17/2012).

\section{Compliance with ethical standards}

Conflict of interest The authors declare that they have no competing interests.

\section{References}

1. Afseth A, Nordlien JH, Scamans GM, Nisancioglu K (2002) Effect of thermo-mechanical processing on filiform corrosion of aluminium alloy AA3005. Corros Sci 44:2491-2506

2. Atik M, Neto P, Avaka LA, Aegreter MA (1995) Sol-gel thin films for corrosion protection. Ceram Int 21:403-406

3. Alinejad S, Naderi R, Mahdavian M (2016) The effect of zinc cation on the anticorrosion behavior of an eco-friendly silane solgel coating applied on mild steel. Prog Org Coat 10:1142-1148

4. Babaev VA, Martynova OI (1984) Justification of selection of water chemistry for power plants with air cooling towers. Teploenergetika 1984(9):63-64

5. Bai X, Ye Z-F, Li Y-F, Zhou L-C, Yang L-Q (2010) Preparation of crosslinked macroporous PVA foam carrier for immobilization of microorganisms. Proc Biochem 45:60-66

6. Bauer AW, Kirby WMM, Sherris JC, Truck M (1966) Antibiotic susceptibility testing by standardized single disk method. Am J Clin Pathol 45:93-496

7. Bedair MA, El-Sabbah MMB, Fouda AS, Elaryian HM (2017) Synthesis, elctrochemical and quantum chemical studies of some prepared surfactants based on azodye and Schiff base as corrosion inhibitors for steel in acid medium. Corros Sci 128:54-57

8. Bera S, Udayabhanu G, Narayan R, Rout TK (2013) Sol-gel process for anti-corrosion coatings. J Res Updates Poly Sci 2:209-231 
9. Brown BF, Foley RT (1980) The chemical nature of aluminum corrosion. Corrosion 36:673-679

10. Cao G, Kou S (2005) Friction stir welding of 2219 aluminum: behavior of $\theta\left(\mathrm{Al}_{2} \mathrm{Cu}\right)$ particles. Weld J 84:1-7

11. Chen $Y$, Jin L, Xie $Y(1998)$ Sol-gel processing of organicinorganic nanocomposite protective coatings. J Sol-Gel Sci Technol 13:735-738

12. Conde A, Duran A, Damborenea JJ (2003) Polymeric sol-gel coatings as protective layers of aluminium alloys. Prog Org Coat 46:288-296

13. Dalmoro V, dos Santos JHZ, Armelin E, Alemán C, Schermann AD (2012) Phosphonic acid/silica-based films: a potential treatment for corrosion protection. Corros Sci 60:173-180. https://doi.org/10.1016/j.corsci.2012.03.040

14. Dubey J, Jeengar N, Upadhyay RK, Chaturvedi A (2012) Corrosion inhibitive effects of Withania Somnifera (a medicinal plant) on aluminium in $\mathrm{HCl}$ solution. Res J Recent Sci 1:73-78

15. El-Naas MH, Mourad AHI, Surkatti R (2013) Evaluation of the characteristics of polyvinyl alcohol (PVA) as matrices for the immobilization of Pseudomonas putida. Int Biodeterior Biodegrad 85:413-420

16. Flemming HC (1996) Economical and technical overview. In: Heitz E, Lemming H-C, Sand W (eds) Microbially influenced corrosion of materials. Springer, Eidelberg

17. Gerasimov VV (1989) Corrosion of reactor materials. Atomizdat, Moscow

18. Ghauch A, Tuqan A, Assi HA (2009) Antibiotic removal from water; elimination of amoxicillin and ampicillin by micro scale and nano scale iron particles. Environ Pollut 157:1625-1626

19. Gu T, Liu X, Chai W, Li B, Sun H (2014) A preliminary research on polyvinyl alcohol hydrogel: a slowly-released anti-corrosion and scale inhibitor. J Petrol Sci Eng 122:453-457

20. Gu Y, Yang L, Chen J, Wang L, Chen B (2015) Hydrogel-swelling driven delivery device for corrosion resistance of metal in water. Water Sci Technol 72:2270-2276

21. Hatch JE (ed) (1984) Aluminium-properties and physical metallurgy. ASM Metals, Park, Ohio

22. Huang C, Kou S (2004) Liquation cracking in full penetration Al-Cu welds. Weld J 83(2):50-58

23. Jiang S, Liu S, Feng W (2011) PVA hydrogel properties for biomedical application. J Mech Behav Biomed Mater 4:1228-1233

24. Kostrikin M, Yu AA, Dzysyuk LP (1971) Toboleva, some notes on water chemistry of unit-type power plants. Teploenergetika 1971(1):74-75

25. Li X, Elliot WL, Zhang W (2006) Zerovalent iron nanoparticles for abatement of environmental pollutants: materials and engineering aspects. Crit Rev Solid State Mater Sci 31:111-122

26. Mcintyre P, Mercer AD (1994) Corrosion testing and determination of corrosion rates. In: Corrosion, vol 19, 3rd edn. pp 19-118

27. McNeill SL, Edwards M (2001) Iron pipe corrosion in distribution systems. J Amer Water Works Assoc 93:88-100. https:// doi.org/10.1002/j.1551-8833.2001.tb09246.x

28. Metals Handbook (1990) Properties of aluminium and aluminium alloys, 10th edn. 2:79-80

29. Metroke T, Apblett A (2004) Effect of solvent dilution on corrosion protective properties of Ormosil coatings on 2024-T3 aluminum alloy. Prog Org Coat 51:36-46

30. Murthy AP, Theerthagiri J, Madhavan J, Murugan K (2017) Hydrogen evolution reaction on highly active $\mathrm{MoS}_{2}$ /carbon electrocatalysts: an insight into the effect of internal resistance and roughness factor on Tafel slope. Phys Chem Chem Phys 19:1988-1998

31. Narenkumar J, Parthipan P, Madhavan J, Murugan K, Babu Marpu S, Suresh A, Rajasekar A (2018) Bioengineered silver nanoparticles as potent anti-corrosive inhibitor for mild steel in cooling towers. Environ Sci Pollut Res 25(6):5412-5420

32. Narenkumar J, Ramesh N, Rajasekar A (2018) Control of corrosive bacterial community by biocide bronopol in industrial water system. 3 Biotech 8(1):55

33. Narenkumar J, Parthipan P, Madhavan J, Murugan K, Suresh A, Rajasekar A (2017) Bio-engineered silver nanoparticles: potent anti-corrosive inhibitor against corrosion of mild steel in cooling towers. Environ Sci Pollut Res 25(6):1-9

34. O'Tool GA, Pratt LA, Watnicr PI, Newman DK, Weaver VB, Kolter $R$ (1999) Genetic approaches to study of biofilm. In: Methods in enzymology, vol 310. Plenum Press, New York, pp 91-109

35. Papadopoulou K, Eliades T (2009) Microbiologically-influenced corrosion of orthodontic alloys: a review of proposed mechanisms and effects. Aust Orthod J 25:63-75

36. Rajasekar A, Ting YP (2011) Role of inorganic and organic medium in the corrosion behavior of Bacillus megaterium and Pseudomonas sp. in stainless steel SS 304. Ind Eng Chem Res 50(22):12534-12541

37. Rajasekar A, Ting YP (2014) Characterization of corrosive bacterial consortia isolated from water in a cooling tower. ISRN Corros 2014:803219. https://doi.org/10.1155/2014/80321910

38. Rajasekar A, Maruthamuthu S, Muthukumar N, Mohanan S, Subramanian P, Palaniswamy N (2005) Bacterial degradation of naphtha and its influence on corrosion. Corros $\mathrm{Sci}$ 47:257-271

39. Satoh $\mathrm{H}$, Odagiri $\mathrm{M}$, Ito $\mathrm{T}$, Okabe $\mathrm{S}$ (2009) Microbial community structures and in situ sulfate-reducing and sulfur-oxidizing activities in biofilms developed on mortar specimens in a corroded sewer system. Water Res 43:4729-4739

40. Selvi A, Das N (2016) Nano-bio hybrid system for enhanced degradation of cefdinir using Candida sp. SMN04 coated with zero-valent iron nanoparticles. J Appl Pharm Sci 6:9-17

41. Selvi A, Banerjee M, Das N (2015) Degradation of cefdinir from pharmaceutical waste water using immobilized Candida sp. SMN04 and biofilm formed on gravels. J Appl Pharm Sci 5:073-079

42. Shaban SM (2016) N-(3-(Dimethyl benzyl ammonio)propyl) alkanamide chloride derivatives as corrosion inhibitors for mild steel in $1 \mathrm{M} \mathrm{HCl}$ solution: experimental and theoretical investigation. RSC Adv 6:39784-39800

43. Suresh AK, Pelletier D, Wonmoon WJ, Nortensen BN, Allison D, Joy D, Phelps T, Mitchel JD (2010) Silver nanocrystallites: biofabrication using Shewanella oneidensis, and an evaluation of their comparative toxicity on gram-negative and gram-positive bacteria. Environ Sci Technol 44:5210-5215

44. Sotondeth K (1981) The chemical nature of aluminum corrosion. Corrosion 37:358-362

45. Sun YP, Li XQ, Cao J, Zhang WX, Wang HP (2007) A method for preparation of stable dispersion of zero-valent iron nanoparticles. Coll Surf A Physicochem Eng Aspects 308:60-66

46. Theerthagiri J, Senthil RA, Buraidah $M H$, Raghavender $M$, Madhavan J, Arof AK (2016) Synthesis and characterization of $\left(\mathrm{Ni}_{1-x} \mathrm{Cox}\right) \mathrm{Se}_{2}$ based ternary selenides as electrocatalyst for triiodide reduction in dye-sensitized solar cells. J Solid State Chem 238:113-120

47. Touira R, Dkhirechea N, EbnTouhamia M, Lakhrissib M, Lakhrissib B, Sfairac M (2009) Corrosion and scale processes and their inhibition in simulated cooling water systems by monosaccharides derivatives. Desalination 249:922-928

48. Zhou C (2014) Polybenzoxazine/ $/ \mathrm{SiO}_{2}$ nanocomposite coatings for corrosion protection of mild steel. Corros Sci 80:269-275

49. Xia C, Xiao C (2012) Preparation and characterization of dual responsive sodium alginateg-poly(vinyl alcohol) hydrogel. J Appl Polym Sci 123:2244-2249 
50. Yasakau KA, Ferreira MGS, Zheludkevich ML (2017) Sol-gel coatings with nanocontainers of corrosion inhibitors for active corrosion protection of metallic materials. In: Klein L, Aparicio $M$, Jitianu A (eds) Handbook of sol-gel science and technology. Springer, Cham, pp 1-37

51. Zarasvand KA, Rai VR (2016) Identification of the traditional and non-traditional sulfate-reducing bacteria associated with corroded ship hull. 3 Biotech 6:197

52. Zhang WX (2003) Nanoscale iron particles for environmental remediation: an overview. J Nanopart Res 5:323-332
53. Zheludkevich ML, Miranda Salvado I, Ferreira MGS (2005) Solgel coatings for corrosion protection of metals. J Mater Chem 15:5099-5111

Publisher's Note Springer Nature remains neutral with regard to jurisdictional claims in published maps and institutional affiliations. 